\title{
Neural correlates of rhythmic expectancy
}

\author{
Theodore P. Zanto ${ }^{1}$, Joel S. Snyder ${ }^{2}$, and Edward W. Large ${ }^{1}$ \\ ${ }^{1}$ Center for Complex Systems and Brain Sciences, Florida Atlantic University \\ 2 Department of Psychiatry, VA Boston Healthcare System/Harvard Medical School
}

Received 20.02.2006

Accepted 18.05.2006

\section{Keywords}

meter, temporal expectancy, auditory perception, gamma-band activity, electroencephalography, rhythm, perception, attention

\section{ABSTRACT}

Temporal expectancy is thought to play a fundamental role in the perception of rhythm. This review summarizes recent studies that investigated rhythmic expectancy by recording neuroelectric activity with high temporal resolution during the presentation of rhythmic patterns. Prior event-related brain potential (ERP) studies have uncovered auditory evoked responses that reflect detection of onsets, offsets, sustains, and abrupt changes in acoustic properties such as frequency, intensity, and spectrum, in addition to indexing higher-order processes such as auditory sensory memory and the violation of expectancy. In our studies of rhythmic expec- tancy, we measured emitted responses - a type of ERP that occurs when an expected event is omitted from a regular series of stimulus events - in simple rhythms with temporal structures typical of music. Our observations suggest that middle-latency gamma band $(20-60 \mathrm{~Hz})$ activity (GBA) plays an essential role in auditory rhythm processing. Evoked (phase-locked) GBA occurs in the presence of physically presented auditory events and reflects the degree of accent. Induced (non-phase-locked) GBA reflects temporally precise expectancies for strongly and weakly accented events in sound patterns. Thus far, these findings support theories of rhythm perception that posit temporal expectancies generated by active neural processes.

\section{INTRODUCTION}

Music and speech are behaviors in which complex sequences of events are exquisitely structured in time. Temporal structuring of acoustic signals is thought to have a profound impact on perception and attention, affording anticipation of when in the future important events are likely to occur (Jones, 1976). Pulse (beat) perception refers to the apprehension of a pseudo-periodic framework underlying the timing of events. The time scale of pulse perception is approximately $100-2000 \mathrm{~ms}(10 \mathrm{~Hz}-0.5 \mathrm{~Hz})$, which corresponds to the range in which humans are most sensitive to tempo change (Drake \& Botte, 1993; Friberg \& Sundberg, 1995), sensorimotor synchronization is possible (Mates, Radil, Muller \& Poppel, 1994; Engström, Kelso \& Holroyd, 1996), and listeners tap with along with music (van Noorden \& Moelants, 1999). Meter percep-

tion refers to the perception of regularity in accent or stress timing, giving rise to a sense of strong and weak beats as illustrated in Figure 1 (Liberman \& Prince, 1977; Lerdahl \& Jackendoff, 1983). It is well established that metric rhythms are easier to remember and reproduce than nonmetric rhythms (Essens \& Povel, 1985), and that individual events are perceptually facilitated in the context of regularly timed sequences (Large \& Jones, 1999; Jones, Moynihan, MacKenzie \& Puente, 2002; Quene \& Port, 2005).

One influential theoretical framework for explaining pulse and meter perception is resonance: the response of an oscillation, exposed to a periodic stimulus, whose frequency stands in some particular

Correspondence concerning this article should be addressed to Theodore P. Zanto, University of California, San Francisco, Mission Bay - Byers Hall, 1700 4th St. Room 102C, San Francisco, CA 94143-2512, zanto@ccs.fau.edu 


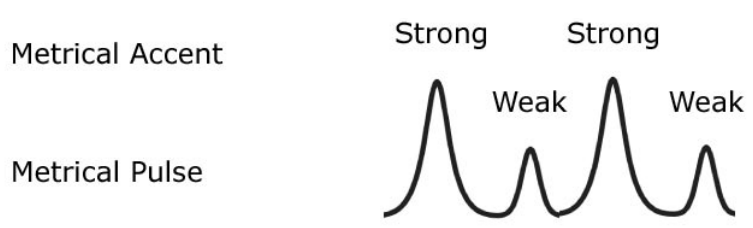

Figure 1.

Graphical representation of a binary metrical structure.

relationship to the oscillator's natural frequency. The primary question is whether linear resonance suffices to explain the perceptual phenomena, or whether it is necessary to posit nonlinear oscillation. Linear resonators, or filters, are passive, stimulus-driven models of rhythm perception. Linear resonators synchronize at the stimulus frequency $(1: 1)$, and increase amplitude as stimulus frequency nears resonator center frequency. Linear models (e.g., Scheirer, 1998; Todd, O'Boyle \& Lee, 1999; Todd, Lee \& O'Boyle, 2002) can extract the amplitude and phase of a rhythm's frequency components, and could, in principle, drive motor output. Nonlinear oscillator models, by contrast, are active, positing an endogenous component in rhythm perception. The two properties of nonlinear resonance most relevant to rhythm perception are synchronization at integer ratios (e.g. 1:1, 2:1, 3:2) of the stimulus frequency (Large \& Kolen, 1994), and endogenous oscillation that can continue in the absence of stimulus events (Large, 2000). It is primarily the latter property that concerns us here.

Dynamic attending theory posits that active "attending rhythms," modeled as nonlinear oscillators, synchronize with the stimulus and generate temporal expectancies for future events (Large \& Jones, 1999). The key prediction is that rhythmic listening involves online temporal anticipation. The experiments described in this article were designed to address this prediction. We aimed to identify neural activity that anticipates events in structured sequences, and persists in the absence of acoustic events. To do this, we employed neurophysiological techniques that allow measurement of anticipation for individual events in rapid acoustic sequences.

Electroencephalography (EEG) and magnetoencephalography (MEG) are the two main techniques for studying the temporal dynamics of auditory processing in the human brain. Investigations measuring EEG and MEG activity have identified short-, middle-, and long-latency responses time locked to the onsets of presented sounds, with principal generators in the brain stem, primary auditory cortex, and secondary auditory cortex, respectively (Picton, Hillyard, Krausz
\& Galambos, 1974; Naatanen \& Winkler, 1999). Many studies have also identified several event-related potentials (ERPs) related to auditory timing and anticipation as discussed below.

\section{ERP CORRELATES OF TIMING AND EXPECTATION}

A number of studies have identified slow cortical potentials that are related to sensory or motor anticipation, and are typically elicited by stimuli on a time scale slower than the time scale at which individual events occur in music and speech. Stimulus preceding negativity (SPN) is a negative deflection originally observed between a motor action and feedback (knowledgeof-results) about the correctness of the movement (Grunewald \& Grunewald-Zuberbier, 1983; Damen \& Brunia, 1985). SPN has been observed in several experimental paradigms relating the SPN to four main types of anticipation: (1) anticipation of feedback, (2) anticipation of an affective stimulus, (3) anticipation of future task instructions and (4) anticipation of probe stimuli in arithmetic tasks (for review, see van Boxtel \& Bocker, 2004). The readiness potential (RP or Bereitschaftspotential) is a negative deflection commencing about one second before a button press and increasing until the motor act (Kornhuber \& Deecke, 1965). RP is of current interest due to the link between rhythm and motor processes. The contingent negative variation (CNV) is a negative deflection observed during the interval between a warning stimulus and a target (Walter, Cooper, Alderidge, McCallum \& Winter, 1964). The interval between stimuli is typically one second or longer and the CNV may be broken into two separate components, early and late (Connor \& Lang, 1969; Weerts \& Lang, 1973). The early CNV component is related to the warning stimulus while the late component has been partially explained by motor anticipation similar to the RP (Gaillard, 1978; Rohrbaugh \& Gaillard, 1983). However, much data shows that non-motor activity may elicit the late CNV component such as viewing slides intended to induce interest (Simons, Ohman \& Lang, 1979) or affect (Klorman \& Ryan, 1980). Thus, it has been suggested that the late CNV component is a combination of motor activity (e.g. RP) and the SPN (Brunia, 1988). Of most interest here is that the CNV is also related to timing an upcoming event (Walter et al., 1964) and tempo perception (Walter et al., 1964; Pfeuty, Ragot \& Pouthas, 2003). Using faster rhythmic stimuli than typically studied with slow cortical potentials, a number of authors have observed emitted potentials (or omitted stimulus potentials), which con- 
sist of brain activity following the expected onset time of a missing event embedded in a regular sequence (Barlow, 1969; Takasaka, 1985). The emitted potential to omitted sounds displays an early modality-specific negative component (Simson, Vaughan \& Ritter, 1976) with a topography and latency similar to the N100, a negative deflection $100 \mathrm{~ms}$ after tone onset (Hughes, Darcey, Barkan, Williamson, Roberts \& Aslin, 2001; Janata, 2001). This earlier component of the emitted potential may reflect mental imagery, rather than a violation of expectation (Janata, 1995; Janata, 2001), as with later components.

For example, a mismatch negativity may be elicited by omitted stimuli, but only for sequences with an inter-onset interval less than 200 ms (Yabe, Tervaniemi, Reinikainen \& Naatanen, 1997; Yabe, Tervaniemi, Sinkkonen, Huotilainen, Ilmoniemi \& Naatanen, 1998). The mismatch negativity (MMN) occurs 120-200 ms following a rare auditory event (oddball) embedded in a sequence of repetitive tones (for review, see (Naatanen, 1990). A rare event may be a change in pitch (Sams, Paavilainen, Alho \& Naatanen, 1985) or intensity (Naatanen, Paavilainen, Alho, Reinikainen \& Sams, 1987), but of interest here is that the MMN may also be elicited by a change in tone duration (Naatanen, Paavilainen \& Reinikainen, 1989) or an interruption of a steady rhythm (Ford \& Hillyard, 1981) such as an omitted stimulus. One interesting aspect of the MMN is that attention does not need to be directed toward the stimuli, indicating that changes are encoded automatically. The MMN is considered an automatic response, and it has been attributed to a memory trace (Naatanen, 1990; Schroger, 1997). It should also be noted that the MMN may be coded by specific neural populations due to the change in topography when different types of rare events are presented (Giard, Lavikainen, Reinikainen, Perrin, Bertrand \& Naatanen, 1995).

Emitted potentials are also observed as a positive peak around $300 \mathrm{~ms}$ after the omitted event and have been equated with the P300, which occurs following an oddball event (Ruchkin \& Sutton, 1978; Rogers, Papanicolaou, Baumann \& Eisenberg, 1992; Besson, Faita, Czternasty \& Kutas, 1997). Brochard, Abecasis, Potter, Ragot \& Drake (2003) utilized an oddball methodology to study subjective accent, a perceptual phenomenon in which isochronous sequences of identical tones are heard as metrically accented (Bolton, 1894). Tones were decremented in intensity at odd (hypothetically strong) or even (hypothetically weak) metrical positions, and P300 responses to deviant tones were observed. Differences in the P300 to odd and even tones suggested that a binary metric structure was perceived. Another study used probe beats in different metrical patterns and observed that the P300 plays a role in metrical processing for musicians (Jongsma, Desain \& Honing, 2004).

To account for the three latencies where emitted potentials may be observed, it should be noted that the N100 and MMN have both exogenous and endogenous influences (for a review, see Naatanen, 1992), and thus may be attributed more to sensory processing compared to the endogenous P300 (for review, see Picton \& Hillyard, 1988). The emitted P300 component has been shown to be attention dependent (Joutsiniemi \& Hari, 1989; Raij, McEvoy, Makela \& Hari, 1997), and displays less latency jitter in rhythmically trained subjects (Jongsma, Quiroga \& van Rijn, 2004). Thus, the emitted MMN and P300 appears to reflect the processing of an expectancy violation while the earlier N100 emitted potential seems to index sensory processing in expectation of an event. Emitted potentials, however, occur after the expected event onset. It is of current interest to find activity preceding the expected onset that might serve to ready the auditory cortex for an event, thereby providing a neural correlate to temporal expectation.

\section{GAMMA BAND CORRELATES OF AUDITORY RHYTHMIC PROCESSING}

High frequency gamma band $(20-60 \mathrm{~Hz})$ activity has been observed to originate in the auditory cortex, separate from the typically observed lower frequency evoked response components (Pantev, Makeig, Hoke, Galambos, Hampson \& Gallen, 1991). Two types of gamma band activity (GBA) have been identified, phase-locked (evoked) and non-phase-locked (induced) activity. Evoked GBA is highly localized in time, independent of tempo (Ross, Picton \& Pantev, 2002; Snyder \& Large, 2004), and may be related to the middle-latency component of the ERP due to its similar source and peak latency. Induced GBA is more temporally variable and may represent less stimulusdriven or cognitive aspects of auditory perceptual processing (Tallon-Baudry \& Bertrand, 1999). Thus, GBA appears to be an ideal candidate for studying the neuroelectric correlates of pulse perception and expectation.

The calculation of evoked and induced activity is depicted in Figure 2. Panel A shows superimposed gamma bursts peaking after a hypothetical stimulus. Non-phase locked gamma bursts are displayed on the left whereas phase-locked bursts are on the right. The results of averaging these types of bursts are shown 
A. Individual Trials
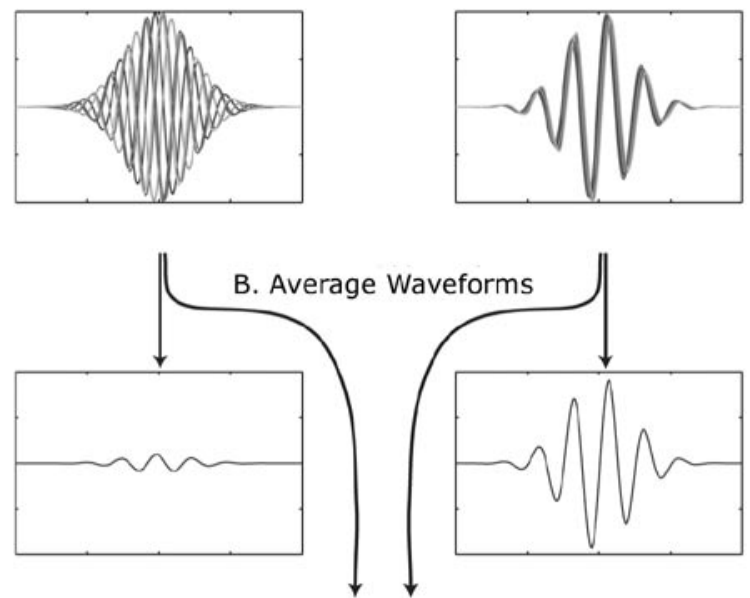

C. Average Envelope
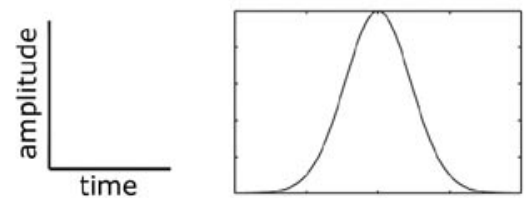

Figure 2.

Calculation of the evoked and induced gamma band activity. (a) Several epochs superimposed with non-phaselocked activity on the left and phase-locked activity on the right. (b). The result of averaging each type of activity from $A$; evoked activity on the right. (c) The average envelope is comparable to the induced activity.

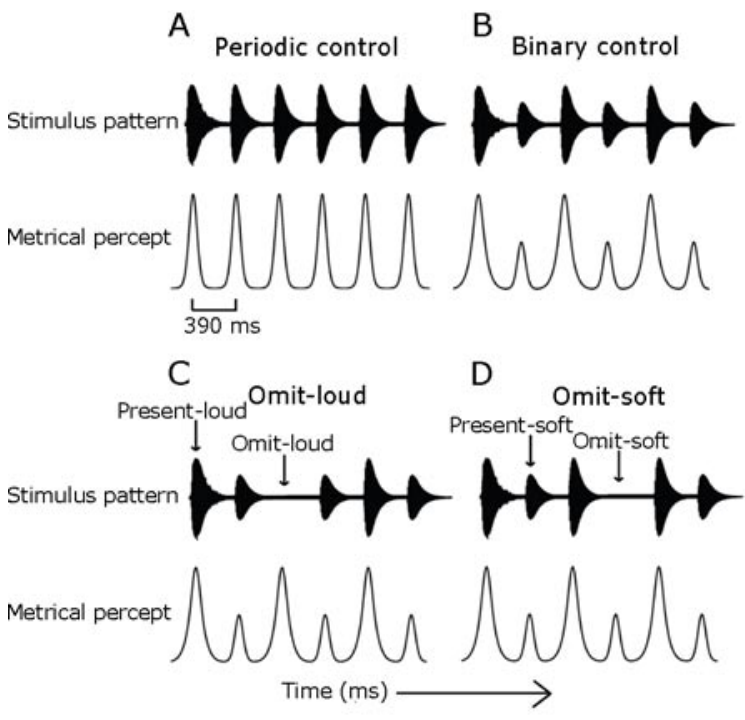

Figure 3.

Four types of stimuli, (a) metronomic control, (b) binary control, (c) omit random loud tones, (d) omit random soft tones.

in panel B. Averaging leads to the evoked response on the right; however, it is apparent that much information is lost when non-phase-locked bursts are averaged together (on the left). Therefore, to avoid canceling out responses of different phases, the en- velope of each individual trial can be calculated before trials are averaged together, which leads to the induced response. This means an evoked response is registered only when the phases of gamma oscillations are time-locked to the stimulus event whereas an induced response requires that the peak amplitude of the gamma activity is time-locked to the stimulus. Although the evoked response may be thought of as a subset of the induced, it has been shown they can exhibit different peak latencies and topographies, and thus can represent different ongoing processes (Bertrand \& Tallon-Baudry, 2000).

The known roles of evoked and induced GBA in auditory perception and object representation led to the hypothesis that the evoked and induced responses may underlie pulse perception and expectation. Given that induced GBA is phase-independent from tone onsets suggests it may play an anticipatory role and display activity prior to tone onset. These features of GBA may help evaluate the theory of dynamic attending proposed by Large and Jones (1999), namely that a fundamental aspect of rhythm perception is the endogenous generation of temporal expectancies.

Snyder and Large (2005) investigated evoked and induced GBA in response to metric rhythms that included missing tones, in order to observe brain activations related to metrical percepts that are independent of physical stimulation. Figure 3 shows a graphical representation of the sound stimulus for each condition as well as the hypothetical internal metrical pattern that may arise from listening to each stimulus. There were two control conditions, one utilizing uniform metronome tones (Figure 3a) and the other utilizing alternating loud and soft tones in a binary meter with no missing tones (Figure $3 \mathrm{~b}$ ). The experimental conditions consisted of alternating loud and soft tones with the loud tone occasionally missing (Figure 3c) and alternating loud and soft tones with the soft tone occasionally missing (Figure $3 d$ ). Figure 4a shows induced and evoked GBA averaged over subjects. For both induced and evoked activity, peaks (dark spots) near tone onsets correspond to stimulus-related responses. Induced activity is observed throughout the analysis epoch ${ }^{1}$, with peaks corresponding to expected acoustic events (i.e. both present and absent tones). The power of evoked and induced GBA followed the loud-soft pattern of the stimuli for the binary control condition when both tones were present (Figure $4 a$, left panels). Induced GBA peaks occurred around tone onset with latency not significantly different than $0 \mathrm{~ms}$, whereas evoked GBA peaks occurred following tone 
A

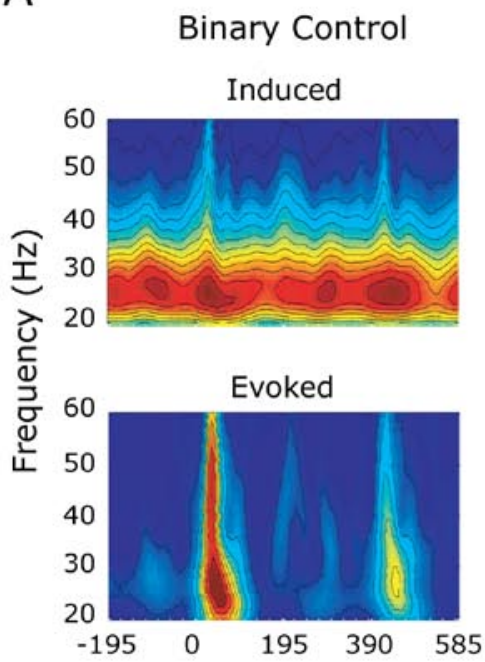

Loud Tone Absent

Induced

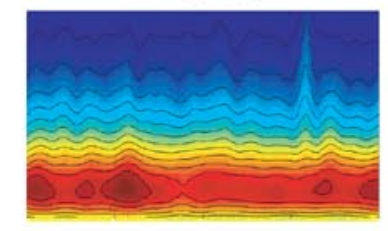

Evoked

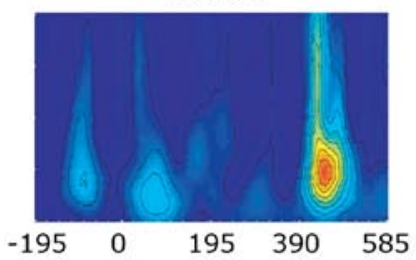

Soft Tone Absent

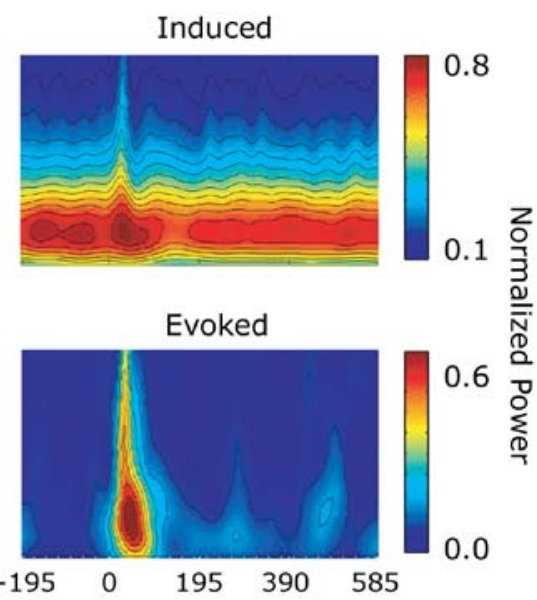

Time (ms)

B
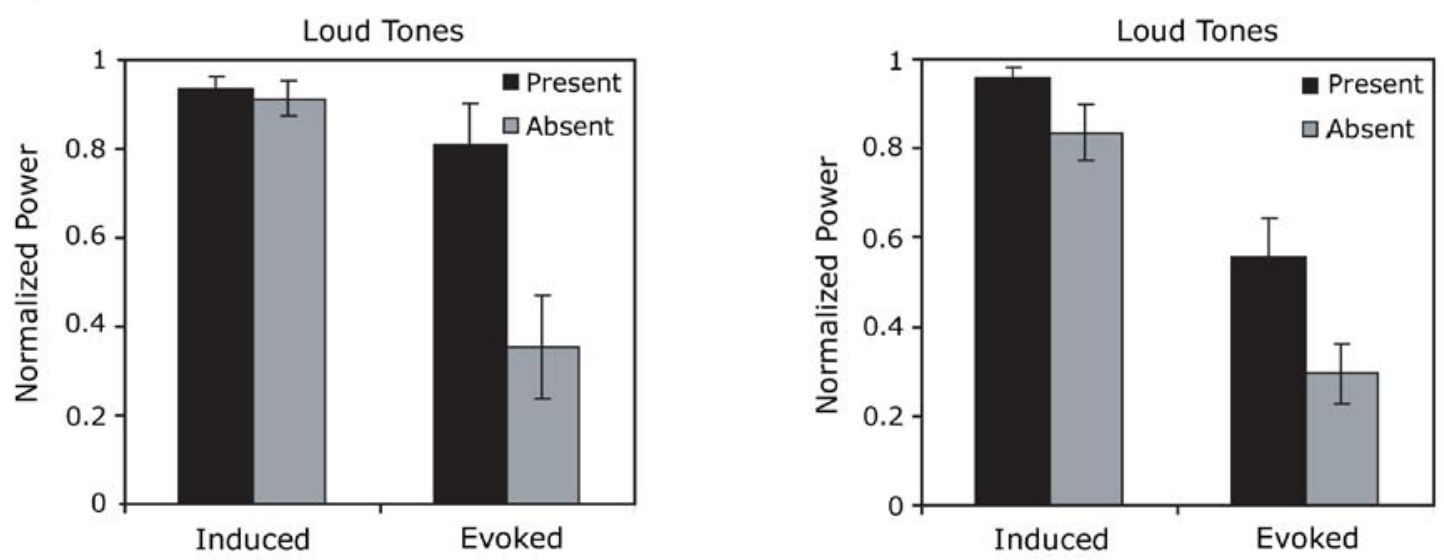

\section{Figure 4.}

(a) Time-frequency representation of the evoked and induced GBA results, averaged over all subjects. Tone onset occurs at zero and 390 ms. (b) Comparison of induced/evoked peak activity in the presence and absence of loud and soft tones.

onset with a latency significantly longer than $0 \mathrm{~ms}$. When the loud tone was omitted, induced GBA was present as in the control condition whereas evoked GBA following the loud tone was greatly diminished in most subjects (Figure 4a, middle panels). A similar result was found when the soft tone was omitted with preserved induced GBA and reduced evoked GBA following the time of the expected tone onset (Figure $4 a$, right panels). The bar graphs of Figure $4 \mathrm{~b}$ show peak power, normalized and averaged over subjects, revealing the interaction between GBA type (evoked / induced) and tone occurrence (present / absent). This interaction indicated that tone omissions resulted in much greater decrease of evoked GBA compared to induced GBA. The occurrence of induced GBA at tone onsets, and its persistence even when tones were omitted suggest induced GBA as a neural correlate of rhythmic expectancy. Furthermore, these properties of induced GBA are consistent with theories of rhythm perception positing endogenous expectancies (Large \& Jones, 1999), which are likely to support a range of human rhythmic abilities such as anticipation of events (Engström et al., 1996), sensitivity to metrical structure (Large \& Jones, 1999; Snyder \& Krumhansl, 2001; Toiviainen \& Snyder, 2003; Hannon, Snyder, Eerola \& Krumhansl, 2004), and the persistence of a metrical representation (Palmer \& Krumhansl, 1990; Large, Fink \& Kelso, 2002).

Using perturbations of a metronome (Figure 5), Zanto, Large, Fuchs \& Kelso (2005) tested the recovery of GBA following an unexpected temporal change. The experiment was designed to create an expecta- 


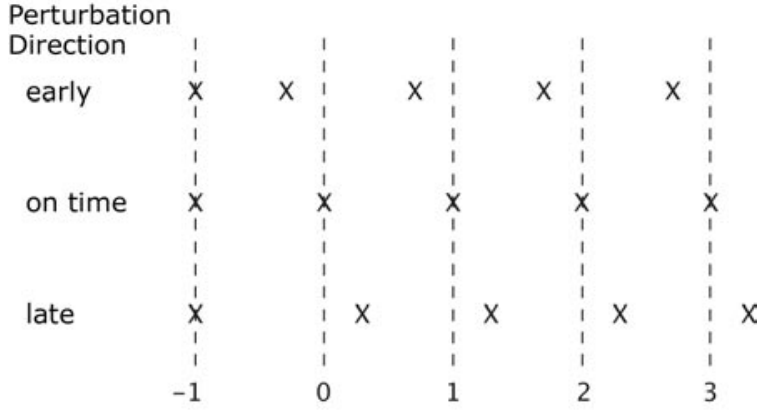

Tone Position

Figure 5.

Perturbed stimuli; ' $x$ ' represents tone onset.

tion for the isochronous auditory events and violate that expectancy every 6-10 tones with an early or late tone onset. It was hypothesized that evoked activity would peak at a set latency regardless of the perturbation whereas induced activity would reflect the expected onset time with the latency recovering back to baseline during subsequent tones. As hypothesized, evoked activity was shown to reflect the presence of tones. However, at the expected temporal location of an early tone, the power of the evoked response was enhanced and surprisingly displayed another (smaller) peak where the tone was expected (Figure $6 a)$. Conversely, the induced response peaked where late tones were expected (Figure 6b). Moreover, the latency of the induced GBA increased for early tones. After both types of perturbation, the latency of the induced activity relaxed to baseline for subsequent tones in a fashion similar to what has been observed in behavioral perturbation studies (e.g., Large et al., 2002; Repp, 2002).

\section{DISCUSSION}

Much research is still necessary to understand the role of gamma activity in auditory perception. Moreover, the links between GBA and other ERP components are not well established. The onset of gamma band processes precedes those of later emitted potentials, but it is not known whether emitted GBA is necessary to elicit the later potentials. If it were necessary, then the case would be strengthened for the view that GBA is a neural correlate for expectation, while later emitted potentials such as the N100, MMN and P300 reflect expectancy violations.

Data from animal studies lend some credibility to this hypothesis. Early emitted potentials have been observed in primary sensory nuclei and modified at midbrain and telencephalic levels (Bullock, Hofmann,
Nahm, New \& Prechtl, 1990; Bullock, Karamursel \& Hofmann, 1993) whereas late (P300) emitted potentials have been recorded within the cat auditory cortex (Basar-Eroglu, Basar \& Schmielau, 1991). Moreover, human EEG studies have shown early emitted potentials to be attention independent whereas the late emitted potentials were attention dependent in both visual (Bullock, Karamursel, Achimowicz, McClune \& Basar-Eroglu, 1994) and auditory (Karamursel \& Bullock, 2000) domains. This leads to the question of the role of GBA in temporal expectancy.

The latency of induced GBA is encompassed by the aforementioned slow-cortical potentials such as the contingent negative variation. This is another unexplored relationship. Due to the strong ties of the CNV and motor activity, further research on CNV may help resolve the nature of auditory sensorimotor synchronization.

Evoked GBA exhibits peak latency similar to the middle-latency response (MLR). Aside from similar latencies, the MLR and the evoked GBA also share a similar origin in or near the primary auditory cortex (Pantev et al., 1991). Moreover, both evoked GBA and the MLR have enhanced amplitudes in response to increased tone intensity (Borgmann, Ross, Draganova \& Pantev, 2001; Snyder \& Large 2005) and increased stimulus rate (Makeig 1990; Pantev, Elbert, Makeig, Hampson, Eulitz \& Hoke, 1993). However, other studies suggest evoked GBA and middle-latency potentials are unaffected by the stimulus rate (Ross et al., 2002; Snyder \& Large 2004). This inconsistency in the literature may stem from the fact that early middle-latency components are less dependent on stimulus rate than later middle-latency components (Erwin \& Buchwald, 1986). It is apparent there is a close relationship between evoked GBA and the MLR but they are not necessarily the same response. The MLR displays a tonotopic organization whereas the evoked GBA does not (Pantev, 1995; Pantev et al., 1995).

Although further research is still needed, GBA displays many important properties that suggest it as a correlate of meter perception. The change in power of the evoked and induced GBA in response to strongly and weakly accented beats suggests sensitivity to a metrical structure. Moreover, the persistence of induced GBA in the absence of tones provides evidence for the perception of pulse, the building block of a meter. These findings are reinforced by the observation that the latency of induced activity mimicks behavioral response to a temporally perturbed metronome.

Recently Iverson, Repp and Patel (2005) measured stimulus-evoked brain responses as listeners manipu- 
A.
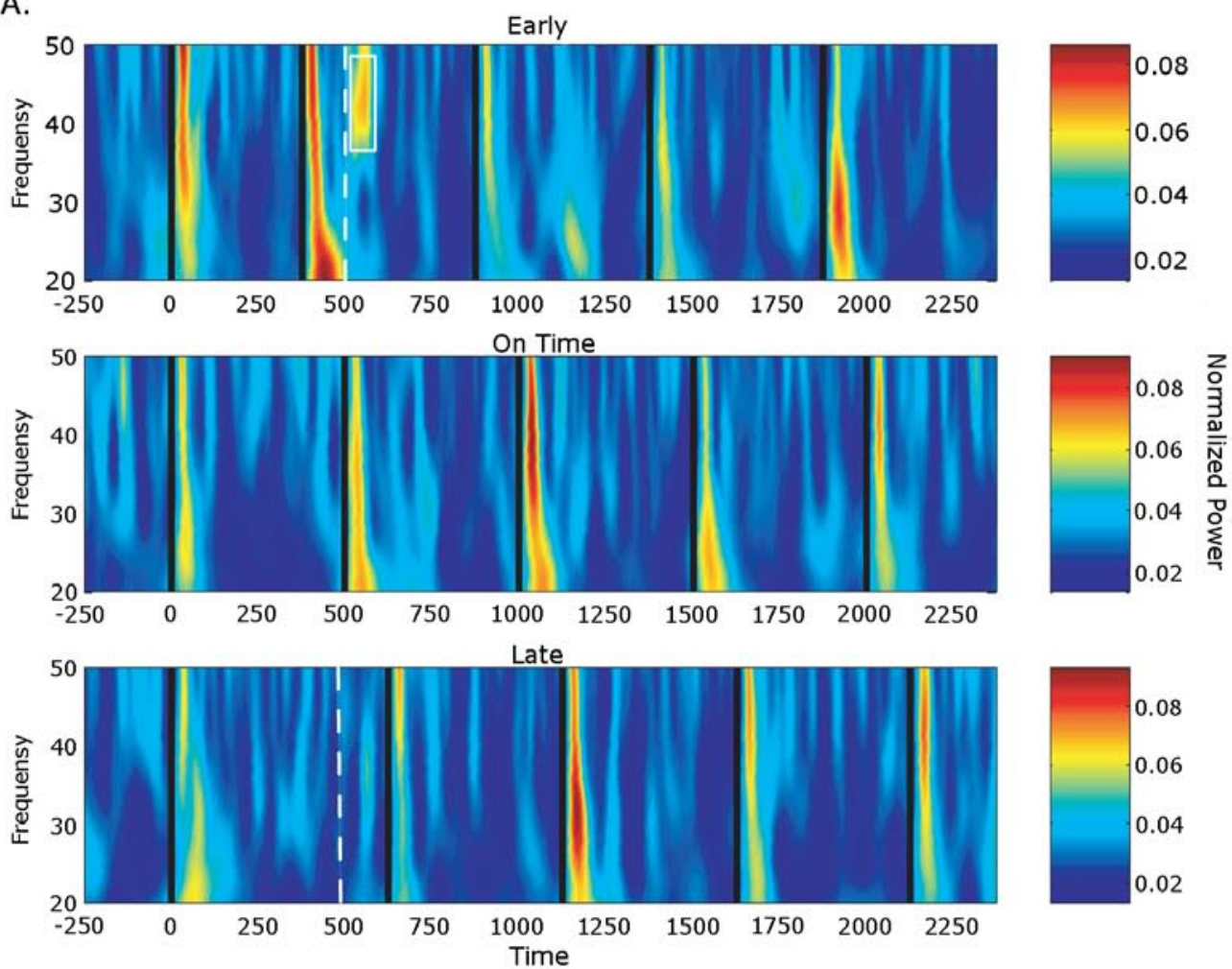

B.
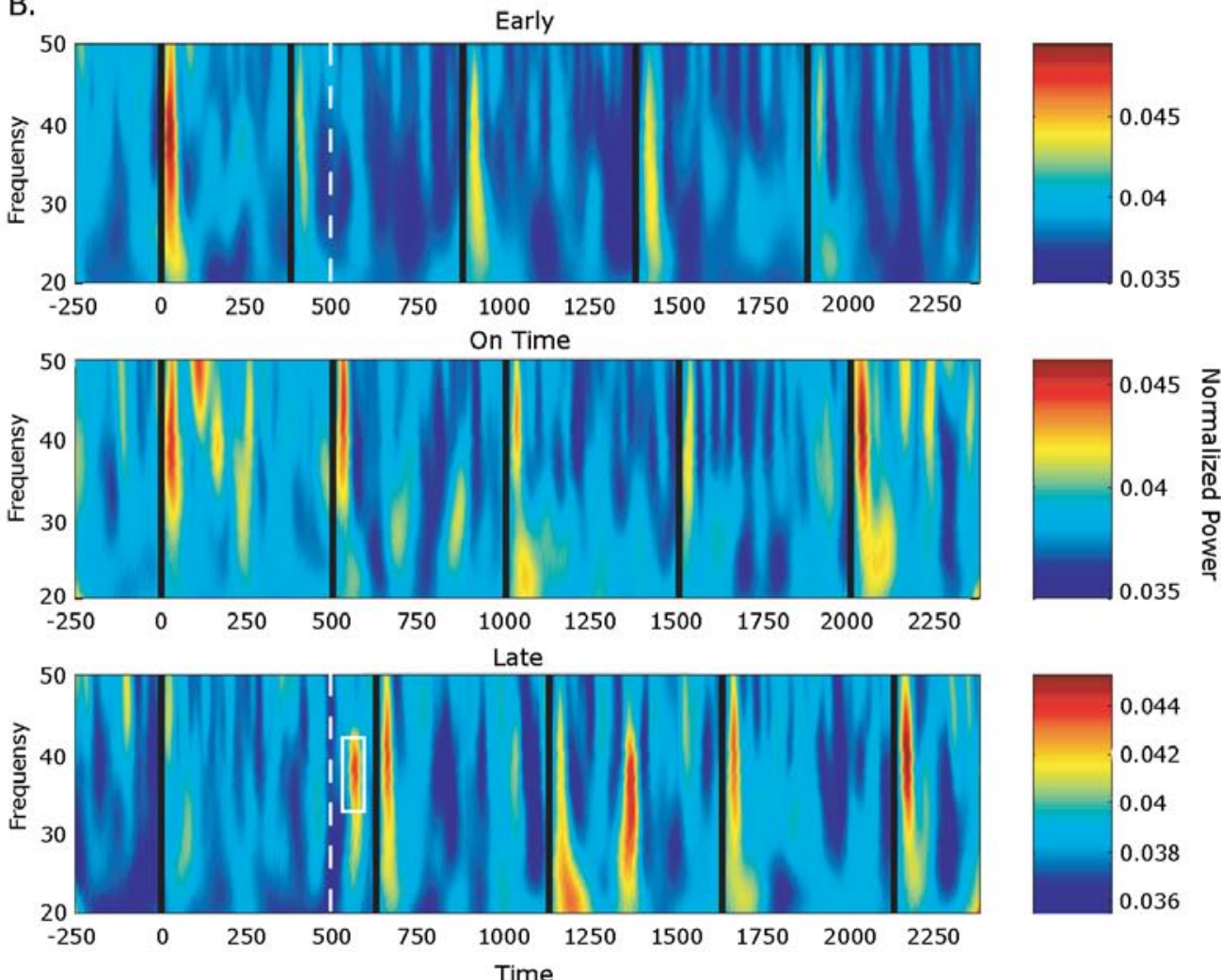

\section{Figure 6.}

Time-frequency representation of the evoked and induced GBA in response to early, late, or on-time tones averaged over all subjects. The white dashed line represents where a tone was expected. (a) Evoked activity is predicted by the presence of tones. The white box highlights an exception, activity where the tone was expected in the case of an early tone. (b) The white box indicates a peak in the induced activity where the tone was expected for the case of late tones. 
lated their metrical interpretation of a simple rhythmic stimulus. They focused on whether response to a sound imagined to be the downbeat was different from the response to the same sound when it was not the downbeat. Indeed, metrical interpretation had a large effect on brain responses in the $20-30 \mathrm{~Hz}$ range, which is included in our definition of GBA. When a tone was imagined to be the downbeat, evoked activity was significantly increased. Because the stimulus events were identical, differences in brain activity must be due to metrical interpretation. This lends support to the notion that responses in this frequency range reflect the perceived meter. Induced activity was not measured in this study.

If GBA were to directly correlate with the perception of meter and behavioral synchronization data, then it might be supposed that induced GBA would display sensitivity to tempo. However, no such sensitivity was observed in response to eight different metronomic rates typical of music (Snyder \& Large 2004). Given the small amplitude of GBA coupled with the known inter- and intra-subject variability from synchronization studies (Mates et al., 1994), an induced GBA tempo dependence may be difficult to observe.

The anticipatory nature of induced GBA provides support for theories of rhythm perception that posit active, forward-looking dynamical processes such as non-linear oscillators. Some oscillator models predict that a perceived metrical pattern arises from an attentional pulse that entrains to the external stimuli and targets attentional energy to expected points in time (Large \& Jones, 1999; Large, 2000). Therefore, the evoked and induced gamma band sensitivity to a metrical structure may display an attentional component. Moreover, understanding the influence of attention may shed light on the relationship between GBA and emitted potentials. The role of attention in GBA should be addressed in future research.

It is interesting to note that some subjects displayed additional induced responses at subdivisions of the tone interval (Snyder \& Large, 2005). Such harmonic responses are nonlinear (Large \& Kolen, 1994) and support approaches that incorporate interval subdivision to explain rate limits of perception and synchronization (London, 2002; Repp, 2003).

\section{SUMMARY}

Evoked GBA appears to represent sensory processing as predicted by the presence of tones, much like the MLR. Induced GBA may reflect temporally precise expectancies for strongly and weakly accented events in sound patterns. Moreover, induced GBA behaves in a manner consistent with perception-action coordination studies using perturbed temporal sequences. Taken together, the characteristics of induced GBA provide evidence for an active, dynamic system capable of making predictions (i.e., anticipation), encoding metrical patterns and recovering from unexpected stimuli.

GBA appears to be a useful neuroelectric correlate of rhythmic expectation and may therefore reflect pulse perception. Due to the anticipatory nature of GBA, it may be supposed there is an attentional dependence. Future research should aim to manipulate attentional state, localize neural sources and further probe the role of induced GBA in meter perception.

\section{Acknowledgments}

Research supported by NSF grant BCS-0094229 and NIMH grant MH42900. A special thanks to Bill McLean for technical support.

\section{Notes}

${ }^{1}$ Calculation of induced activity discards phase information resulting in the preservation of background activity. Moreover, inter-subject timing variability contributes to the appearance of continual activity in the grand average.

\section{References}

Barlow, J. S. (1969). Some observations on the electrophysiology of timing in the nervous system. Electro-encephalography and Clinical Neurophysiology, 27, 545.

Basar-Eroglu C., Basar E., \& Schmielau F. (1991). P300 in freely moving cats with intracranial electrodes. International Journal of Neuroscience, 60, 215-226. www

Bertrand, O. \& Tallon-Baudry, C. (2000). Oscillatory gamma activity in humans, a possible role for object representation. International Journal of Psychophysiology, 38, 211-223. |WWW

Besson, M., Faita, F., Czternasty, C., \& Kutas, M. (1997). What's in a pause: event-related potential analysis of temporal disruptions in written and spoken sentences. Biological Psychology, 46, 3-23. |www| Bolton, T. L. (1894). Rhythm. American Journal of Psychology, 6, 145-238.

Borgmann, C., Ross, B., Draganova, R., \& Pantev, C. (2001). Human auditory middle latency responses: influence of stimulus type and intensity. Hearing Research, 158, 57-64. www

Brochard, R., Abecasis, D., Potter, D., Ragot, R., \& Drake, C. (2003). The tick-tock of our internal clock: direct brain evidence of subjective accents in isochronous 
sequences. Psychological Science, 14, 362-366.

Brunia, C. H. (1988). Movement and stimulus preceding negativity. Biological Psychology, 26, 165-178. Www Bullock T.H., Hofmann M.H., Nahm F.K., New J.G., \& Prechtl J.C. (1990). Event-related potentials in the retina and optic tectum of fish. Journal of Neurophysiology, 54, 903-914.

Bullock, T.H., Karamursel, S. \& Hofmann, M.H. (1993). Interval-specific event related potentials to omitted stimuli in the electrosensory pathway in elasmobranches: an elementary form of expectation. |WWW Journal of Comparative Physiology, 172, 501-510.

Bullock, T.H., Karamursel, S., Achimowicz, J.Z., McClune, M.C. \& Basar-Eroglu, C. (1994). Dynamic properties of human visual evoked and omitted stimulus potentials. Electroencephalography and Clinical Neurophysiology, 91, 42-53.

Connor, W. H. \& Lang, P. J. (1969). Cortical slow wave and cardiac rate responses in stimulus orientation and reaction time conditions. Journal of Experimental Psychology, 82, 310-320. |WwW

Damen, E. J. P. \& Brunia, C. H. M. (1985). Slow brain potentials related to movement and visual feedback in a response timing task. Biological Psychology, 20, 195.

Drake, C. \& Botte, M. (1993). Tempo sensitivity in auditory sequences: evidence for a multiple-look model. Perception and Psychophysics, 54, 277286. |WWw

Engström, D. A., Kelso, J. A. S., \& Holroyd, T. (1996). Reaction-anticipation transitions in human perception-action patterns. Human Movement Science, 15, 809-822.

Erwin, R. J., \& Buchwald, J. S. (1986). Midlatency auditory evoked-responses: differential recovery cycle characteristics. Electroencephalography and Clinical Neurophysiology, 64, 417-423. [ww]

Essens, P. J. \& Povel, D. (1985). Metrical and nonmetrical representation of temporal patterns. Perception and Psychophysics, 37, 1-7.

Ford, J. M. \& Hillyard, S. A. (1981). Event-related potentials (ERPs) to interruptions of steady rhythm. Psychophysiology, 13, 32-39. Www

Friberg, A. S. \& Sundberg, J. (1995). Time discrimination in a monotonic, isochronous sequence. Journal of the Acoustical Society of America, 98, 25242531.

Gaillard, A. W. K. (1978). Slow brain potentials preceding task performance. Amsterdam: Academic Press.

Giard, M. H., Lavikainen, J., Reinikainen, K., Perrin, F., Bertrand, O., \& Naatanen, R. (1995). Separate representations of stimulus frequency, intensity, and duration in auditory sensory memory: an event-related potential and dipole-model analysis. Journal of Cognitive Neuroscience, 7, 133-143.

Grunewald, G. \& Grunewald-Zuberbier, E. (1983). Cerebral potentials during voluntary ramp movements in aiming tasks. In A. W. K. Gaillard, W. Ritter (Eds.), Tutorials in ERP research: Endogenous components. (pp. 311-327). Amsterdam: NorthHolland.

Hannon, E. E., Snyder, J.S., Eerola, T., \& Krumhansl, C.L. (2004). The role of melodic and temporal cues in perceiving meter. Journal of Experimental Psychology: Human Perception and Performance, 30, 988-1015. |www

Hughes, H. C., Darcey, T. M., Barkan, H. I., Williamson, P. D., Roberts, D. W., \& Aslin C. H. (2001). Responses of human auditory association cortex to the omission of an expected acoustic event. Neuroimage, 13, 1073-1089. WWW

Iversen, J. R., Repp, B. H., \& Patel, A. D. (2005). Metrical interpretation modulates brain responses to rhythm sequences. Poster presentation at The Neurosciences and Music II: From Perception to Performance Conference in Leipzig, 1060. Annals of the New York Academy of Sciences.

Janata, P. (1995). ERP measures assay the degree of expectancy violation of harmonic contexts in music. Journal of Cognitive Neuroscience, 7, 153-164.

Janata, P. (2001). Brain electrical activity evoked by mental formation of auditory expectations and images. Brain Topography, 13, 169-93. WwW

Jones, M. R. (1976). Time, our lost dimension: toward a new theory of perception, attention, and memory. Psychological Review, 83, 323-335. www

Jones, M. R., Moynihan, H., MacKenzie, N., \& Puente, J. (2002). Temporal aspects of stimulus-driven attending in dynamic arrays. Psychological Science, 13, 313-319. www

Jongsma, M., Desain, P., \& Honing, H. (2004). Rhythmic context influences the auditory evoked potentials of musicians and nonmusicians. Biological Psychology, $66,129-152$. $\overline{w W w}$

Jongsma, M., Quiroga, R. Q., \& van Rijn, C. M. (2004). Rhythmic training decreases latency-jitter of omission evoked potentials (OEPs) in humans. Neuroscience Letters, 355, 189-192. |Ww|

Joutsiniemi, S. L. \& Hari, R. (1989). Omissions of auditory-stimuli may activate frontal-cortex. European Journal of Neuroscience, 1, 524-528. WwW

Karamursel, S. \& Bullock, T.H. (2000). Human auditory fast and slow omitted stimulus potentials and steady-state responses. International Journal of 


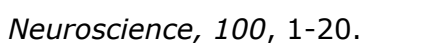

Klorman, R. \& Ryan, R. M. (1980). Heart rate, contingent negative variation, and evoked potentials during anticipation of affective stimulation. Psychophysiology, 17, 513-523. |www

Kornhuber, H. H. \& Deecke, L. (1965). Hirnpotentialanderungen bei Willkurbewegungen und passiven Bewegungen des Menschen: Bereitschaftspotential und reafferente Potentiale [Brain potential changes during arbitrary and passive movements in humans: Bereitschaftspotential and reafferent potentials]. Pflugers Archiv, 284, 1-17.

Large, E. W. (2000). On synchronizing movements to music. Human Movement Science, 19, 527-566.

Large, E. W. \& Kolen, J. F. (1994). Resonance and the perception of musical meter. Connection Science, 6 , 177-208.

Large, E. W. \& Jones, M. R. (1999). The dynamics of attending, How we track time varying events. Psychological Review, 106, 119-159.

Large, E. W., P. Fink, \& Kelso, J. A. S. (2002). Tracking simple and complex sequences. Psychological Research, 66, 3-17. |Ww|

Lerdahl, F. \& Jackendoff, R. (1983). A generative theory of tonal music. Cambridge: MIT Press.

Liberman, M. \& Prince, A. (1977). On stress and linguistic rhythm. Linguistic Inquiry, 8, 249-336.

London, J. (2002). Cognitive constraints on metric systems: Some observations and hypotheses. Music Perception, 19, 529-550.

Makeig, S. (1990). Auditory event related dynamics of the EEG spectrum and effects of exposure to tones. Electroencephalography and Clinical Neurophysiology, 86, 283-293. Www

Mates, J., Radil, T., Muller, U., \& Poppel, E. (1994). Temporal integration in sensorimotor synchronization. Journal of Cognitive Neuroscience, 6, 332-340.

Naatanen, R. (1990). The role of attention in auditory information processing as revealed by event-related potentials and other brain measures of cognitive function. Behavioral and Brain Sciences, 13, 201-288.

Näätänen, R. (1992). Attention and Brain Function. Lawrence Erlbaum Associates: Hillsdale.

Naatanen, R., Paavilainen, P., Alho, K., Reinikainen, K., \& Sams, M. (1987). The mismatch negativity to intensity changes in an auditory stimulus sequence. Electroencephalography and Clinical Neurophysiology Supplement, 40, 125-131. Www

Naatanen, R., P. Paavilainen, \& Reinikainen, K. (1989). Event-related potentials to infrequent decrements in duration of auditory stimuli demonstrate a memory trace in man. Neuroscience Letters, 107,

\section{7-352. WWW}

Naatanen, R. \& Winkler, I. (1999). The concept of auditory stimulus representation in cognitive neuroscience. Psychological Bulletin, 125, 826-59.

Palmer, C. \& Krumhansl, C. L. (1990). Mental representations for musical meter. Journal of Experimental Psychology: Human Perception and Performance, 16, 728-41. |www

Pantev, C. (1995). Evoked and induced gamma band activity of the human cortex. Brain Topography, 7, 321-330. $\mid \underline{w W \mid}$

Pantev, C., Makeig, S., Hoke, M., Galambos, R., Hampson, S., \& Gallen, C. (1991). Human auditory evoked gamma-band magnetic fields. Proceedings of the National Academy of Sciences of the United States of America, 88, 8996-9000. Www

Pantev, C., Elbert, T., Makeig, S., Hampson, S., Eulitz, C., \& Hoke, M. (1993). Relationship of transient and steadystate auditory evoked fields. Electroencephalography and Clinincal Neurophysiology, 88, 389 - 396. Www

Pantev, C., Bertrand, O., Eulitz, C., Erkindt, C., Hampson, S., Schuierer, G., \& Elbert, T. (1995). Specific tonotopic organization of different areas of the human auditory cortex revealed by simultaneous magnetic and electric recordings. Electroencephalography and Clinincal Neurophysiology, 94, 26-40. |WWw

Pfeuty, M., Ragot, R., \& Pouthas, V. (2003). Processes involved in tempo perception: a CNV analysis. Psychophysiology, 40, 69-76.

Picton, T. W., Hillyard, S.A., Krausz, H.I., \& Galambos, R. (1974). Human auditory evoked potentials. I. Evaluation of components. Electroencephalography and Clinical Neurophysiology, 36, 179-190.

Picton, T.W. \& Hillyard, S.W. (1988). Endogenous event related potentials. In T.W. Picton (Ed.), Handbook of Electroencephalography and Clinical Neurophysiology (Vol. 3): Human Event Related Potentials (pp. 361-426). Amsterdam: Elsevier.

Quene, H. \& Port, R. F. (2005). Effects of timing regularity and metrical expectancy on spoken-word per-

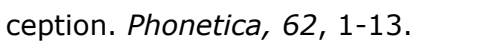

Raij, T., McEvoy, L., Makela, J.P., \& Hari, R. (1997). Human auditory cortex is activated by omissions of auditory stimuli. Brain Research, 745, 134-43. Www

Repp, B. H. (2002). Phase correction in sensorimotor synchronization: nonlinearities in voluntary and involuntary responses to perturbations. Human Movement Science, 21, 1-37.

Repp, B.H. (2003). Rate limits in sensorimotor synchronization with auditory and visual sequences: the synchronization threshold and the benefits and costs of interval subdivision. Journal of Motor Behavior 35, 
355-370.

Rogers, R. L., Papanicolaou, A. C., Baumann, S. B., \& Eisenberg, H. M. (1992). Late magnetic fields and positive evoked potentials following infrequent and unpredictable omissions of visual stimuli. Electroencephalography and Clinical Neurophysiology, 83, 146-152.

Rohrbaugh, J. W. \& Gaillard, A. W. K. (1983). Sensory and motor aspects of the contingent negative variation. In A. W. K. Gaillard \& W. Ritter (Eds.), Tutorials in ERP research: Endogenous components (pp. 269310). Amsterdam: North-Holland.

Ross, B., Picton, T.W., \& Pantev, C. (2002). Temporal integration in the human auditory cortex as represented by the development of the steady-state magnetic field. Hearing Research, 165, 68-84.

Ruchkin, D. S. \& Sutton, S. (1978). Emitted P300 potentialsandtemporaluncertainty. Electroencephalography and Clinical Neurophysiology, 45, 268-277.

Sams, M., Paavilainen, P., Alho, K., \& Naatanen, R. (1985). Auditory frequency discrimination and event-related potentials. Electroencephalography and Clinical Neurophysiology, 62, 437-448. Www

Scheirer, E. D. (1998). Tempo and beat analysis of acoustic musical signals. Journal of the Acoustical Society of America, 103, 588-601. [WwW

Schroger, E. (1997). On the detection of auditory deviations: a preattentive activation model. Psychophysiology, 34, 245-257. [www]

Simons, R. F., Ohman, A., \& Lang, P. J. (1979). Anticipation and response set: cortical, cardiac, and electrodemal correlates. Psychophysiology, 16, 222-233. |WwW

Simson, R., Vaughan, H. G., \& Ritter, W. (1976). The scalp topography of potentials associated with missing visual or auditory stimuli. Electroencephalography and Clinical Neurophysiology, 40, 33-42. Www

Snyder, J. S. \& Krumhansl, C. L. (2001). Tapping to ragtime: cues to pulse finding. Music Perception, 18, 455-489.

Snyder, J. S. \& Large, E. W. (2004). Tempo dependence of middle and long latency auditory responses: power and phase modulation of the EEG at multiple timescales. Clinical Neurophysiology, 115, 1885-1895. Www

Snyder, J. S. \& Large, E. W. (2005). Gamma-band activity reflects the metric structure of rhythmic tone sequences. Cognitive Brain Research, 24, 117-126. [WW'
Takasaka, Y. (1985). Expectancy-related cerebral potentials associated with voluntary time estimation and omitted stimulus. Folia Psychiatrica et Neurologica Japonica, 19, 251-268. www

Tallon-Baudry, C. \& Bertrand, O. (1999). Oscillatory gamma activity in humans and its role in object representation. Trends in Cognitive Sciences, 3, 151-162. |WwW|

Todd, N. P. M., O'Boyle, D. J., \& Lee, C. S. (1999). A sensory-motor theory of rhythm perception. Journal of New Music Research, 28, 1-24.

Todd, N. P., Lee, C. S., \& O'Boyle, D. J. (2002). A sensorimotor theory of temporal tracking and beat induction. Psychological Research, 66, 26-39. |www

Toiviainen, P. \& Snyder, J. S. (2003). Tapping to Bach: resonance-based modeling of pulse. Music Perception, 21, 43-80.

van Boxtel, G. J. M. \& Bocker, K. B. E. (2004). Cortical measures of anticipation. Journal of Psychophysiology, 18, 61-76.

van Noorden, L. \& Moelants, D. (1999). Resonance in the perception of musical pulse. Journal of New Music Research, 28, 43-66.

Walter, W. G., Cooper, R., Alderidge, V. J., McCallum, W. C., \& Winter, A. L. (1964). Contingent negative variation: an electric sign of sensori-motor association and expectancy in the human brain. Nature, 203, 380-384.

Weerts, T. C. \& Lang, P. J. (1973). The effects of eye fixation and stimulus and response location on the contingent negative variation (CNV). Biological Psychology, 1, 1-19. |WwW

Yabe, H., Tervaniemi, M., Reinikainen, K., \& Naatanen, R. (1997). Temporal window of integration revealed by MMN to sound omission. Neuroreport, 8, 1971-1974. $\underline{w w w}$ Yabe, H., Tervaniemi, M., Sinkkonen, J., Huotilainen, M., Ilmoniemi, R.J., \& Naatanen, R. (1998). The temporal window of integration of auditory information in the human brain. Psychophysiology, 35, 615-619. WWw

Zanto, T. P., Large, E. W., Fuchs, A., \& Kelso, J. A. S. (2005). Gamma-band responses to perturbed auditory sequences: Evidence for synchronization of perceptual processes. Music Perception, 22, 535-552 